\title{
Interannual population dynamics of the green spruce aphid Elatobium abietinum (Walker) in France
}

by Lempiere, G., Day, K.R., Petit-Berghem,Y., Robinet, N., Portier, P., Leather, S.R. and Marage, D.

Copyright, publisher and additional information: this is the author accepted manuscript. The final published version (version of record) is available online via Wiley. This article may be used for non-commercial purposes in accordance with Wiley Terms and Conditions for Self-Archiving.

Please refer to any applicable terms of use of the publisher.

DOI: $\underline{\text { https://doi.org/10.1111/aab.12560 }}$

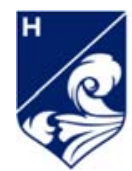




\section{Annals of Applied Biology}

An international journal of the aab

\section{Interannual population dynamics of the green spruce aphid Elatobium abietinum (Walker) in France}

\begin{tabular}{|r|l|}
\hline Journal: & Annals of Applied Biology \\
\hline Manuscript ID & AAB-2019-0188.R1 \\
\hline Manuscript Type: & Original Article \\
\hline Author: & 29-Aug-2019 \\
\hline Complete List of Authors: & $\begin{array}{l}\text { LEMPERIERE, Guy; Laboratoire d'Écologie Alpine, Ecologie fonctionnelle } \\
\text { Day, Keith; University of Ulster, Environmental Science; } \\
\text { PETIT-BERGHEM, Yves; ecole nationale supérieure de paysage, ecology } \\
\text { Robinet, Nicolas; Université Grenoble Alpes Institut d'Urbanisme et de } \\
\text { Géographie Alpine, Cermosem } \\
\text { Portier, Perrine; Laboratoire d'Écologie Alpine, Ecologie fonctionnelle } \\
\text { Leather, Simon; Harper Adams University College Department of Crop } \\
\text { and Environment Sciences, Crop \& Environment Sciences } \\
\text { MARAGE, Damien; LADYSS, Université Paris 1 Panthéon Sorbonne }\end{array}$ \\
\hline Key Words: & $\begin{array}{l}\text { Elatobium abietinum, Picea sitchensis, Population Dynamics, Forest } \\
\text { Management, Biodiversity, Climate }\end{array}$ \\
\hline
\end{tabular}

\section{SCHOLARONE \\ Manuscripts}


Running head: RESEARCH ARTICLE

\section{Interannual population dynamics of the green spruce aphid Elatobium abietinum (Walker) in France}

Guy Lemperiere ${ }^{1}$, Keith R Day ${ }^{2}$, Yves Petit-Berghem ${ }^{3}$, Nicolas Robinet ${ }^{4}$, Pérrine Portier ${ }^{1}$, Simon R Leather ${ }^{5} \&$ Damien Marage ${ }^{6}$

${ }^{1}$ LECA, UMR CNRS 5553, Université Grenoble Alpes (UGA), BP 53, 38041 Grenoble Cedex 9, France

${ }^{2}$ School of Environmental Sciences, University of Ulster, Coleraine BT52 1SA, Northern Ireland, UK

${ }^{3}$ LAREP, Ecole Nationale Supérieure du Paysage, 10, rue Maréchal Joffre, 78000 Versailles, France

${ }^{4}$ Cermosem, Institut de Géographie Alpine (IGA), UMR CNRS PACTE Université Grenoble Alpes (UGA), Domaine Olivier de Serres, Le Pradel, 07170 Mirabel, France

${ }^{5}$ Crop and Environmental Sciences, Harper Adams University, Edgmond, Newport, TF10 $8 \mathrm{NB}, \mathrm{UK}$

${ }^{6}$ LADYSS, UMR CNRS 7533, 2 rue Valette, 75005 Paris, France.

\section{Correspondence}

Damien Marage, LADYSS, UMR CNRS 7533, 2 rue Valette, 75005 Paris, France. Email: marage.damien@gmail.com

\section{Keywords}

Elatobium abietinum, Picea sitchensis, Population time series, Climate, Forest management, Environment

Received: 31 May 2019; revised version received: 29 August 2019; accepted: 18 October 2019.

\section{Summary}

- Context The hypothesis that similar processes govern interannual dynamics of green spruce aphid in the UK and France, is generally supported by the application of a general discrete model. A simple model based on relatively few parameters was able to closely characterise interannual population dynamics from completely independent aerial and arboreal samples of aphids. Long term field population estimates of the green spruce aphid Elatobium abietinum (Walker) in France have provided the 
opportunity to select and evaluate the generality of a model which was developed in the UK to explain the year-to-year variations in peak abundance of the aphid.

- Aims The objective was to observe the influence of the local climates and disturbing climate factors on the population densities of the insect in two regions of France.

- Methods The model uses climate variables and aphid population data from regular samples in the two regions that were investigated. A general discrete model was used to predict aphid population densities.

- Results The model performed well in tracking the interannual patterns of population but was less likely to predict absolute population density.

- Conclusion To improve predictions, further account would need to be taken of additional site-specific climate variables and the strength of overcompensating density dependence. Nevertheless it is clear that broadly similar processes are at work in the population dynamics of this insect across its biogeographical range. 


\section{1 | Introduction}

The green spruce aphid Elatobium abietinum Walker 1949 (Homoptera: Aphididae) is one of the seven species of the genus Elatobium Mordvilko 1914 which belongs to the subfamily Aphidinae and tribe Macrosiphini (Remaudière and Remaudière 1997). Three of those species are conifer feeders (Blackman \& Eastop, 1994). Of these, E. abietinum is the major pest of Sitka spruce Picea sitchensis (Bong.) Carr. throughout northern and western Europe where this tree species has been abundantly planted in reforestation areas since the early $1950 \mathrm{~s}$ (Hanson, 1952; Carter, 1977; Parry, 1969; Day, 1984b; Day \& Crute, 1990) (Fig. 1).

This sap-feeding insect was first described feeding on Norway spruce Picea abies (L.) Karst. which might be the original and normal host of E. abietinum. This host tree can tolerate heavy infestations without suffering severe defoliation and shows less reaction to its presence than does Sitka spruce (Carter \& Nichols, 1988; Day \& McClean, 1991). Norway spruce appears to have had time to evolve resistance mechanisms to the aphid forcing the insect to switch to a more susceptible host-plant.

The life cycle of the insect (Fig. 2) is dependent on the local climate and it is admitted that under maritime climates like in the UK but also in Normandy and Brittany, western France, anholocyclic populations are governed by low winter temperatures (Powell \& Parry, 1976) while in more continental regions like the Limousin (France) and the Massif Central (France) or in Denmark (Harding \& Carter, 1997) holocyclic populations overwinter as dormant eggs. In Brittany and Normandy, the aphids overwinter as wingless viviparous females but severe frost in these regions will result in high aphid mortality.

Parthenogenetic reproduction can continue at low temperatures and aphids are present in large numbers at the end of winter when temperatures become more favourable for the insect (Day et al. 2004). There is a period of maximum increase in the number of aphids 
during the spring damaging period when the needles contain a high concentration of aminoacids which is required by the insect (Carter \& Nichols, 1988). Peak density is reached in May. After bud flush, nutrients are moved to the newly formed needles which remain unattacked for up to 4 months after flushing. At the same time, in late spring, a winged viviparous female form (alatae) disperses and populations collapse until late summer, early autumn when the tree produces hard terminal buds and is in a dormant shoot growth condition. Simultaneously, the aphid starts increasing in numbers (Day op.cit.).

Elatobium abietinum only feeds on mature needles causing chlorotic bands while current-year needles deter aphid feeding (Carter \& Nichols, op.cit.). These old needles rapidly become yellow and are prematurely abscissed. Trees that have suffered heavy damage have thin crowns and reduced annual rings. The aphid is especially damaging in winter on dormant trees. Substantial needle losses can cause a reduction in growth and hence timber yield which can be affected for two or three years after the attack (Straw \& Green, 2001).

With the economic consequences of green spruce aphid population growth in mind, a numerical model of long-term trends in peak population has been developed using relatively few parameters and incorporating knowledge of endogenous and exogenous factors influencing population dynamics (Day et al., 2009). This initiative was particularly promising because it robustly described field data derived not only from aphids feeding on trees in Northern Ireland but also from alate aphids in suction traps from Scotland. The potential for describing geographically independent data sets suggested that this model might perform equally well elsewhere in Europe.

In this investigation we examine a time series obtained over 12 years in two French forests. We hypothesise that the essential features of spruce aphid interannual population dynamics, endogenous density dependent feedback and exogenous weather factors, will play out in a similar way wherever anholocyclic populations of the aphids are found on Sitka 
spruce in western Europe. Populations in northern and western France are a good test of the generality of this hypothesis, and are a considerable geographical distance from the regions for which the model we employ was originally developed. 


\section{2 | Materials and methods}

\section{1 | Host-plant an aphid population data}

A cartographic study of Sitka spruce plantations over the two regions has been carried using the IFN data set (Inventaire Forestier National, 1999) and regional vegetation maps (CORINE Land Cover France, 2009) and included an extensive field survey of Sitka spruce plantations. The aphid populations were assessed using the protocol as described below.

The aphid population time series was derived from estimates of aphid abundance on spruce needles at the forest of Monnaye (Normandy) $\left(02^{\circ} 08^{\prime} \mathrm{W}, 48^{\circ} 51^{\prime} \mathrm{N}\right.$, mean elevation $280 \mathrm{~m})$ and forest of Malaunay (Brittany) $\left(03^{\circ} 05^{\prime} \mathrm{W}, 48^{\circ} 54^{\prime} \mathrm{N}\right.$, mean elevation $\left.135 \mathrm{~m}\right)$.

Both forests are privately owned and managed by private forest experts. The forest of Monnaye is located in the department of the Orne and covers 620.3 ha including 64 ha of Sitka spruce. The forest of Malaunay is located in the Côtes d'Armor on the north coast of Brittany and covers 672 ha including 296 ha of Sitka spruce.

Four forests compartments of different ages (forest plots planted in 1954 and 1967 in Monnaye; forest planted in 1965 and 1990 in Malaunay) have been selected in the two forests and sampled at regular intervals every two weeks from 1997 up to 1999 and four times per year from 2000 until 2008 providing a representation of year-to-year fluctuations in abundance (Day \& Crute, 1990). The abundance of aphid populations within and between trees was assessed using a transect method called Central Point Quarter Method (CPQM) (Dahdouh-Guebas \& Koedam, 2006) in the four forests plots that were visited. 80 trees per random transect were sampled using the modified plotless technique CPQM. This plot-less method involves measuring distances for a random sample of trees, typically along a transect, and recording the characteristics of interest for this sample. The advantage to using plot-less methods rather than standard plot-based techniques is that they tend to be more efficient. Plot- 
less methods are faster, require less equipment, and are not dependent on the size of quadrats. Many authors tested and stated that CPQM will highly recommended and used in forest inventory (Cottam \& Curtis, 1956 ; Beasom \& Haucke, 1975). For each tree, five branches were collected in a total of 400 samples per forest plot and date.

Population estimates were expressed as mean total aphids per 100 needles and sample shoot in order to standardize the results with existing protocols (Day, 1984b, 1986).

In particular, the samples capture the point at which the aphid population reaches its annual maximum, and this has been used to represent annual populations in the analysis.

\section{2 | Climate variables}

The selection of climate variables and metrics was based on their known relationship to aphid population processes. The green spruce aphid passes the entire year anholocyclicly as nymph or adult and as such its rate of development, and that of its populations are at least partly temperature dependent. A decline in availability of plant sap nutrients following spruce budburst means that aphids can benefit most from higher temperature prior to this point. Thermal time (phys) accumulated through the months prior to budburst reflected the ability of aphids to develop and reproduce, and hence was likely to be linked to population growth. On the other hand, spruce aphids are susceptible to subzero temperatures, despite their ability to supercool, and a metric reflecting this was incorporated in earlier versions of the population model. However, when tested with UK field data no signal of demographic effects from this metric was found in the model as winters in the areas from which UK data was derived were insufficiently severe. Another low temperature metric (coma) was derived to account for aphid mortality by starvation or chill coma experienced after prolonged periods when temperature is below the aphid developmental threshold. These two climate variables became 
the most successful metrics in generating a model applied to spatially heterogeneous independent data (Day et al., 2009).

\section{3 | Model description and application}

\subsection{1 | General description and background}

We employed a general discrete model of population dynamics (Turchin \& Taylor, 1992) where interannual per capita growth rate $=R_{t}=\ln \left(N_{t} / N_{t-1}\right)$ where $N_{t}=N_{t-1} x e^{R}$ (with $N_{t}=$ aphid abundance in late spring of year $t$ ). We also hypothesized that there would be negative feedback (density-dependence) on aphid abundance i.e., $R_{t}=f\left(N_{t}\right)+\varepsilon_{t}$, with $\varepsilon$ representing sampling error in density estimates plus exogenous (density-independent) effects on aphid population dynamics. Thus we evaluated alternative models for climatic effects on aphid populations by examining relations between $\varepsilon$ and specific climate parameters.

Alternative models for climatic effects were compared with respect to three criteria: (1) the pattern with respect to climate should be consistent with theoretical expectations (e.g., extreme winter cold is expected to yield lower per capita growth rates); (2) a model that includes one or more climatic drivers should be defensibly favoured over simpler alternative models based upon information theory; (3) and we favoured models in which the regression coefficients that were retained were statistically distinguishable from 0 . Our rationale for the latter criterion was that most of the statistical null hypotheses were nontrivial (e.g. spring rain, a variable tested but discarded, might or might not matter to aphid populations). We began analyses with shoot-based aphid abundance data collected over a period of 10 years in Northern Ireland, identified the best models for this data set, tested those models against independent 37 year time series data on aerial abundance from Scotland and then settled on a single model, as follows, that could reasonably be applied to both situations. 
$R=4.74( \pm 0.40)-1.28( \pm 0.11) \cdot \ln (N)-0.047( \pm 0.20) \cdot$ coma $+0.0045( \pm 0.0014) \cdot$ phys [Eq.1]

This was the model used in the present study with mean daily temperature records obtained from the local Meteo France stations in Dinard and Côtes d'Armor for Brittany and Pré-en-ail, Orne for Normandy.

Population densities of aphids were predicted using this model for each year and forest area (Normandy and Brittany).

\subsection{2 | Model parameters \\ phys}

Physiological time (Campbell et al., 1974; Day, 1984a; Fisher \& Dixon, 1986; Crute \& Day, 1990; Day \& Crute, op.cit.; Day et al., 2004, op.cit.) is the thermal time accumulated from 1 January to the approximate date of budburst respectively 20 April for Brittany and 30 April for Normandy. It has been assumed that growth and reproduction are temperature dependent (Day et al. 2004) and that $4^{\circ} \mathrm{C}$ is the threshold for aphid development. Phys expressed in degree days is then a function that accumulates degree days above $4^{\circ} \mathrm{C}$ over the period which is most favourable for aphid development. In the development of the model, values of physiological time were adjusted for each year relative to the site average to yield the metric phys.

coma

Prefreeze mortality is known to be potentially important for spruce aphids living in maritime climates (Powell \& Parry, 1976; Bale et al., 1988; Dixon, 1998). To account for this the number of chill days with a daily mean temperature $\leq 5^{\circ} \mathrm{C}$ from 1 October to budburst was 
recorded. The metric coma used in the model was then represented by the number of chill periods, each a consecutive run of 5 days with daily mean temperature of $\leq 5^{\circ} \mathrm{C}$. 


\section{3 | Results}


In Normandy, the forest of Monnaye belongs to the Seine biogeographical region. The average temperature of $10^{\circ} \mathrm{C}$ is lower and the moisture greater than in the neighbouring departments. The west winds are the most frequent and the rainfall, distributed over 160 up to 180 days annually, amounts to nearly $100 \mathrm{~cm}$, or half as much again as the average for France. Consequently, aphids experience cold winters and low temperatures which affect the population dynamics by reducing the growth in winter (Carter, 1972; Day et al., 2009, op.cit.). Aphid physiological time (phys) was variable (between 290.5 and 606.6 day $^{\circ} \mathrm{C}$ ) as a result of cold or mild winter and spring weather. Warm weather with a large accumulation of physiological time as observed in 1998, 1999, 2002, 2003 and 2007 allowed a rapid aphid recruitment and population growth. Periods showing a number of five consecutive chill days with a daily mean temperature $\leq 5^{\circ} \mathrm{C}$ from 1 October to budburst (coma) had a negative effect on population growth (Powell \& Parry, 1976; Day \& Crute, 1990) as observed in 1997, 2005 and 2006. The two metrics phys and coma were negatively correlated $(r=-0.65)$ for this site. Aphid populations remained relatively low and below a threshold where visible damage to foliage would be widespread.

The forest of Malaunay, on the north coast of Brittany is influenced by the Gulf Stream and by constant west winds bringing wet air from the Atlantic Ocean. The resulting moderate oceanic climate is characterized by mild winters and lime summers. An average temperature of $12^{\circ} \mathrm{C}$ is observed on the coast and rarely come under zero while an average temperature of $10^{\circ} \mathrm{C}$ is recorded inland. Relative humidity remains high over the year. The west wind blowing practically constantly brings wet air from the Atlantic Ocean that it rains relatively often even if rain quantities are not particularly important. Aphid physiological time (phys) was variable (between 280 and 508.9 day $^{\circ} \mathrm{C}$ ) as a result of cold or mild winter and spring weather. Warm weather with a large accumulation of physiological time as observed in 
1997, 1999, 2001, 2007 and 2008 allowed a rapid aphid recruitment and population growth (Fig. 3a and b). As seen at Monnaye, periods showing a number of five consecutive chill days with a daily mean temperature $\leq 5^{\circ} \mathrm{C}$ from 1 October to budburst (coma) had a negative effect on population growth (Powell \& Parry, 1976; Day \& Crute, 1990) as observed in 1999, 2005 and 2006. The two metrics phys and coma were negatively correlated $(r=-0.65)$ for this site. Climate metrics that were used in the model consistently explained the variations in field data (Day et al., 2009).

The annual populations of aphids predicted by the model and informed by local meteorological data, were not close to observed values in absolute terms but the predicted patterns of change from year to year were very similar to those observed (Fig. 4). Endogenous, overcompensated regulation is strongly signaled by the "see-saw" fluctuation of observed populations, something that is captured well in the model. While populations in Normandy remained relatively low, and below a threshold where visible damage to foliage would be widespread, populations in Brittany tended to fluctuate around a higher equilibrium density and occasionally (4 out of 12 years) rose to a level at which needle loss would be expected. 


\section{4 | Discussion}

Intra-annual population dynamics of green spruce aphid follow a familiar pattern in Western Europe and have been attributed to the combined influences of the thermal environment, host plant sap quality, aphid dispersal and predation (Day, 1984, 1986; Day at al., 2004, 2006; Straw et al., 2009). By contrast, the trajectory of populations across years was less studied until very long-term data became available through the Rothamsted Insect Survey (Harrington et al., 1992). Green spruce aphids suction-trapped during their early summer flight period across Great Britain became an accepted surrogate for aphid population density at a local level and with 40 years of data it was possible to assess the influence of the North Atlantic Oscillation (NAO), and latitudinal gradients in climate effects, on inter-annual changes (Saldana et al., 2007; Westgarth-Smith et al., 2007; Lima et al., 2008). Day et al. (2009) demonstrated similarities between the data obtained from suction traps and more intensively sampled foliar habitats where the aphids spend most of their lives. A simple model based on relatively few parameters was able to closely characterize interannual population dynamics from completely independent aerial and arboreal samples of aphids. This was made possible by a unique 9-year time series of forest aphid data (Day et al., 2009).

The hypothesis that similar processes govern interannual dynamics of green spruce aphid in the UK and France, is generally supported by the application of a general discrete model developed for aphid data in the north of the UK, to aphid populations in northern France. The model had a tendency to overestimate population density in France because values of phys in France (12 year means, Normandy 332,5; Brittany 412) are understandably well above those experienced in Northern Ireland and Scotland (78 year mean East Craigs, 239). We deduce that aphid populations in the Phys period (January to April) did not increase at a rate anticipated by the model which was derived from lower UK Phys values. Despite 
warmer spring conditions in France, aphids were unable to take advantage by developing more quickly, probably because needle sap nutrients remained low for a greater proportion of the Phys period.

The effects of winter temperature on aphids in France was probably similar to that in the northern UK. Aphids in Northern Ireland and Scotland showed no demographic effects from accumulated degree days below $-7^{\circ} \mathrm{C}$ (Day et al., 2009) but were sensitive to sustained « chill periods ». The coma metric showed that the French forests were not colder in winter than those in Scotland included in the model (mean coma values, Normandy 3.7, Brittany 7.6 and East Craigs 11.2) (Fig. 5). The observed French populations demonstrate the"see-saw" fluctuations resulting from overcompensated density dependence. This type of behaviour is common in aphid populations associated with trees (Sequeira \& Dixon, 1997) and arises from a number of processes such as discussed by Day et al. (2009).

Records in western France show that the aphid has existed on non-indigenous spruce forests like Sitka spruce plantations since the 1950s (Joly, 1961). This pattern did not seem to affect the dispersal ability of aphid populations. It has been assumed that increases in mean temperatures at local and regional scales might increase the abundance of aphid populations over the next 50-100 years and that newly planted trees might experience more severe defoliations (Straw, 1995; Straw et al.m 1998a,b).

Green spruce aphid outbreaks that have affected the health and growth of Sitka spruce through successive regular defoliations, as observed in the UK (Carter \& Nichols, 1988; Thomas \& Miller, 1994) have occurred in Normandy and Brittany every 10 years as confirmed by our study and by historical records in 1958 (Joly, 1961), 1968 (Leroy \& Malphettes, 1969). Heavy defoliations were also observed in the Limousin in 1968 by Leroy \& Malphettes (1969) and in 1999 during our survey. 
Sitka spruce has been successfully introduced in the two regions by foresters since the middle of the $19^{\text {th }}$ century (Leroy \& Malphettes, op.cit.) and more intensively planted following major projects of wetland afforestation and/or reforestation since the 50 s covering a total surface of nearly 20000 ha for the two regions. Changes in land use including forest and conservation issues have had a quick and deep impact on the plantations of Sitka spruce and consequently aphid populations in the two regions. A major change in the management of public forests has led to the restoration of wetlands while private forestry is still using Sitka spruce in reforestation areas (Lemperiere et al., in prep.). As a result, the patches that have been formed by the Sitka spruce plantations within large agricultural landscapes follow a pattern which is linked with the nature of the soil. Most of those patches are not connected and could then be considered as biogeographical islands (Woiwod \& Hanski, 1992). Metapopulations of the green spruce aphid that were mostly distributed throughout the Sitka spruce growing areas seem to follow this general patchiness which was observed in the two regions.

Another major impact on aphid distribution could be a shift from Sitka spruce to Norway spruce which is considered as its normal host in northern Europe (Austara et al., 1997; Halldorsson et al., 2004) and causing more cryptic damages as observed in some parts of the Alps (Fig. 6). An interesting complementary study could be carried out to improve the model since the observed outbreaks that have occurred after the last field assessments in 2008 (local annual reports for Normandy and Brittany from the Département de Santé des Forêts surveys on forest pests) confirm that the general model performs well in tracking the interannual trajectories of the populations from 2008 up to 2018 with outbreaks in 2012 and 2015 in Brittany and 2014 and 2017 in Normandy. 


\section{Acknowledgements}

11

12

13

14

15

16

17

18

19

21

22

23

24

25

27

28

29

30

31

33

34

35

36

37

38

39

40

41

42

43

44

45

46

47

48

49

50

51

52

53

54

55

56

57

58

59

60 
The research programme FAIR-3PL96-N1792 RESPHORAPHID was financed by the European Union. 


\section{References}


Austarå, Ø., Carter, C., Eilenberg, J., Halldórsson, G., \& Harding, S. (1997). Natural enemies of the green spruce aphid in spruce plantations in maritime North-West Europe. Icelandic Agricultural Sciences, 11, 113-124.

Bale, J.S., Harrington, R., \& Clough, M.S. (1988). Low temperature mortality of the peachpotato aphid Myzus persicae. Ecological Entomology, 13, 121-129.

Beasom, S., \& Haucke, H. (1975). A comparison of four distance sampling techniques in south texas live oak mottes. Journal of Range Management, 28, 142-144.

Blackman, R.I., \& Eastop, V.F. (1994). Aphids on the world's trees. Wallingford, UK: CAB International.

Campbell, A., Frazer, B.D., Gilbert, N., Gutierrez, A.P., \& Mackauer, M. (1974). Temperature requirements of some aphids and their parasites. Journal of Applied Ecology, 11, $431-438$.

Carter, C.I. (1972). Winter temperatures and survival of the green spruce aphid, Elatobium abietinum (Walker). Forest Rec. (Forestry Commission, UK), 84, 1-10.

Carter, C.I. (1977). Impact of Green Spruce Aphid on growth: can a tree forget its past? Forestry Commission Research and Development Paper, 116, 1-8.

Carter, C.I., \& Nichols, J.F.A. (1988). The Green Spuce Aphid and Sitka Spruce Provenances in Britain. Forestry Commission Occasional Paper, 19, 1-7.

Crute, S., \& Day, K.R. (1990). Understanding the impact of natural enemies on spruce aphid populations through simulation modeling. In Population dynamics of forest insects, pp. 29337. Eds A.D. Watt, S.R. Leather, M.D. Hunter and N.A.C. Kidd. Andover: Intercept.

Cottam, G., \& Curtis, J. (1956). The use of distance measure in phytosociological sampling. Ecology, 37, 451-460. 
Dahdouh-Guebas, F., \& Koedam, N. (2006). Empirical estimate of the reliability of the use of the point- centred quarter method (pcqm): Solutions to ambiguous field situations and description of the pcqm+ protocol. Forest Ecology and Management, 228, 1-18.

Day, K.R. (1984a). The growth and decline of a population of the spruce aphid Elatobium abietinum during a three year study, and the changing Pattern of fecundity, recruitment and alary polymorphism in a Northern Ireland Forest. Oecologia, 64,118-124.

Day, K.R. (1984b). Systematic differences in the population density of green spruce Aphid, Elatobium abietinum in a provenance trial of Sitka spruce, Picea sitchensis. Annals of Applied Biology, 105, 405-412.

Day, K.R. (1986). Population growth and spatial patterns of spruce aphids (Elatobium abietinum) on individual trees. Journal of Applied Entomology, 102, 505-515.

Day, K.R., \& Cameron, A. (1996). Effect of contemporary infestation by the spruce Aphid (Elatobium abietinum) on root growth in Sitka spruce transplants. Forestry, 70, 1-5.

Day, K.R., \& Crute, S. (1990). The abundance of spruce aphid under the influence of an oceanic climate. Population dynamics of forest insects, pp. 25-33. Eds A.D. Watt, S.R. Leathe, M.D. Hunter and N.A.C. Kidd. Andover: Intercept.

Day, K.R., Docherty, M., \& Armour, H. (2004). Population responses of a conifer-dwelling aphid, to seasonal changes in its host. Ecological Entomology, 29, 555-566.

Day, K.R., Ayres, M.P., Harrington, R., \& Kidd, N.A.C. (2009). Interannual dynamics of aerial and arboreal green spruce aphid populations. Population Ecology, 52, 317-327.

Day, K.R., \& McClean, S.I. (1991). Influence of the green spruce aphid on defoliation and radial stem growth of Sitka spruce. Annals of Applied Biology, 119, 415-423.

Dixon, A.F.G. (1998). Aphid ecology: an optimization approach. London: Chapman and Hall. Fisher, M., \& Dixon, A.F.G. (1986). Role of photoperiod in the timing of dispersal in the green spruce aphid Elatobium abietinum. Journal of Animal Ecology, 55,657-667. 
Halldorsson, G., Sigurrdsson, V., Thorsson, A.Th., Oddsdottir, E.S., Sigurgeirsson, A., \& Anamthawat-Jonsson, K. (2004). Genetic diversity of the green spruce aphid Elatobium abietinum Walker in north-west Europe. Agricultural and Forest Entomology, 6, 31-37.

Hanson, H.S. (1952). The green spruce aphid, Neomyzaphis abietina Walker. Forestry Commission Report on Forest Research 1951, pp. 98-104.

Harding, S., \& Carter, C.I. (1997). First record of males, oviparae and eggs of the Green spruce aphid Elatobium abietinum (Walker) in Denmark. Ent. Meddr, 65, 175-178.

Harrington, R., \& Woiwod, I.P. (2007). Foresight from hindsight: the Rothamsted insect survey. Outlooks on Pest Management, 18, 9-14.

Joly, R. (1961). Les causes animales dans le jaunissement et la chute des aiguilles de l'épicéa de Sitka Picea sitchensis et d'autres épicéas. Revue Forestière Française, 3, 179-186.

Lemperiere et al. in prep. Ecologie et biogéographie du Puceron vert en France. Revue Forestière Française.

Leroy, P., \& Malphettes, C.B. (1969). Premières constatations sur les attaques du Puceron vert vis-à-vis des plantations de Sitka installées en mauvais sol dans l'ouest de la France. Revue Forestière Française, 21, 547-550.

Lima, M., Harrington, R., Saldana, S., \& Estay, S. (2008). Non-linear feedback processes and a latitudinal gradient in the climatic effects determine green spruce aphid outbreaks in the UK. Oikos, 117, 951-959.

Parry, W.H. (1969). A study of the relationship between defoliation of Sitka spruce and population levels of Elatobium abietinum (Walker). Forestry, 42, 69-82.

Powell, W., \& Parry, W.H. (1976). Effects of temperature on overwintering populations of the green spruce aphid Elatobium abietinum. Annals of Applied Biology, 82, 209-219.

Remaudière, G., \& Remaudière, M. (1997). Catalogue of the world's Aphididae (Homoptera Aphidoidea). Paris: Institut National de la Recherche Agronomique. 
Saldana, S., Lima, M., \& Estay, S. (2007). North Atlantic Oscillation effects on the temporal and spatial dynamics of spruce aphid populations in the UK. Journal of Animal Ecology, 76, $782-789$.

Sequeira, R., \& Dixon, A.F.G. (1997). Population dynamics of tree-dwelling aphids: the importance of seasonality and time scale. Ecology, 78, 2603-2610.

Straw, N.A. (1995). Climate change and the impact of green spruce aphid, Elatobium Abietinum (Walker), in the UK. Scottish Forestry, 49, 134-145.

Straw, N.A., \& Green, G. (2001). Interactions between green spruce aphid (Elatobium Abietinum (Walker)) and Norway and Sitka spruce under high and low nutrient conditions. Agricultural and Forest Entomology, 3, 263-274.

Straw, N.A., Halldorsson, G., \& Benedikz, T. (1998a). Damage sustained by individual trees: empirical studies on the impact of the green spruce aphid. In The Green Spruce Aphid in Western Europe; ecology, status, impacts and prospects for management. Eds K.R. Day, G. Halldorsson, S. Harding and N.A. Straw. Forestry Commission, Technical paper, 24, 15-31. Straw, N.A., Fielding, N.J., Green, G., \& Coggan, A. (1998b). The impact of green spruce aphid Elatobium abietinum (Walker) on the growth of young Sitka spruce in Hafren Forest, Wales: pattern of defoliation and effect on shoot growth. Forest Ecology and Management, 104, 209-225.

Straw, N.A., Timms, J.E.L., \& Leather, S.R. (2009). Variation in the abundance of invertebrate predators of the green spruce aphid Elatobium abietinum (Walker) (Homoptera: Aphididae) along an altitudinal transect. Forest Ecology and Management, 258, 1-10.

Thomas, R.C., \& Miller, H.G. (1994). The interaction of green spruce aphid and Fertilizer applications on the growth of Sitka spruce. Forestry, 67, 329-342.

Turchin, P., \& Taylor, A.D. (1992). Complex dynamics in ecological time series. Ecology, 73, 289-305. 
Westgarth-Smith, A.R., Leroy, S.A.G., Collins, P.E.F., \& Harrington, R. (2007). Temporal variations in English populations of a forest insect pest, the green spruce aphid (Elatobium abietinum), associated with the North Atlantic Oscillation and global warming. Quaternary International, pp. 173-174; 153-160.

Woiwod, I.P., Hanski, I. (1992). Patterns of density dependence in moths and aphids. Journal of Animal Ecology, 61, 619-629.

\section{Figure Legends}

Fig. 1 Distribution of the green spruce aphid Elatobium abietinum (Walker) (in grey) and Norway spruce (hatched) in Europe. After Halldorsson et al.2004, redrawn from (Anon., 1966) and Sigurgeirsson \& Szmidt, 1992.

Fig. 2 Life cycles of Elatobium abietinum after Carter \& Halldorsson (1998).

Fig. 3 Population time series for Elatobium at Monnaye (Normandy) (a) and Malaunay (Brittany) (b), France. Mean aphid population density $(n=400$ samples) at annual peak population (April/June) each year.

Fig. 4 Population time series for Elatobium at Monnaye (Normandy) (a) and Malaunay (Brittany) (b), France. Mean aphid population density $(n=400$ samples) at annual peak population (April/June) each year.

Fig. 5 Historical patterns in two climatic metrics relevant to the population dynamics of Elatobium abietinum patterns near Monnaye (Normandy) and Malaunay (Brittany) and .East Craigs, Scotland (1951-2007).

Fig. 6 Distribution of Sitka spruce in France and location of study sites with presence and absence of Elatobium abietinum (1997-2008). 


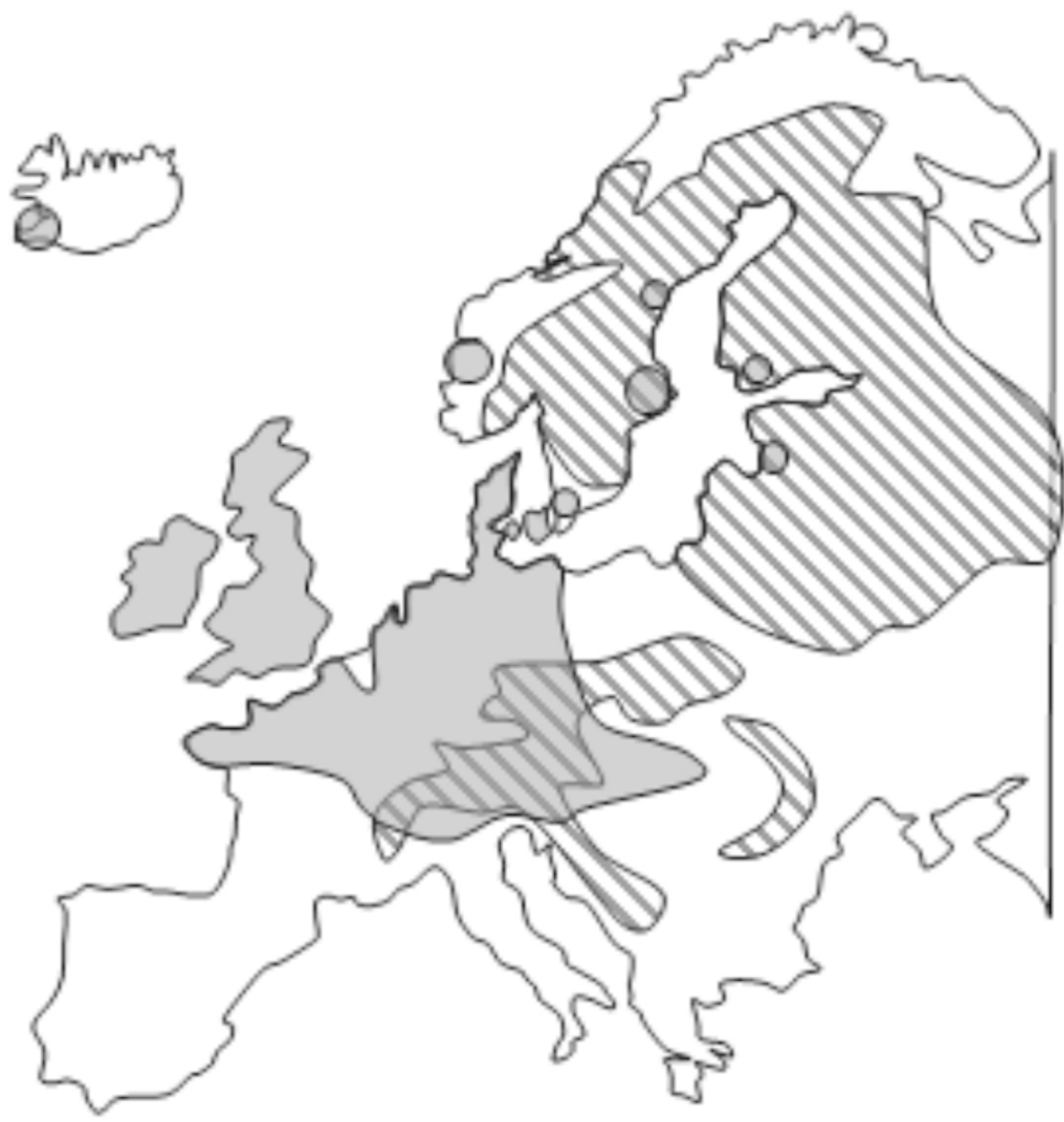

Distribution of the green spruce aphid Elatobium abietinum (Walker) (in grey) and Norway spruce (hatched) in Europe. After Halldorsson et al. (2004), redrawn from Anon. (1966) and Sigurgeirsson \& Szmidt (1992). 


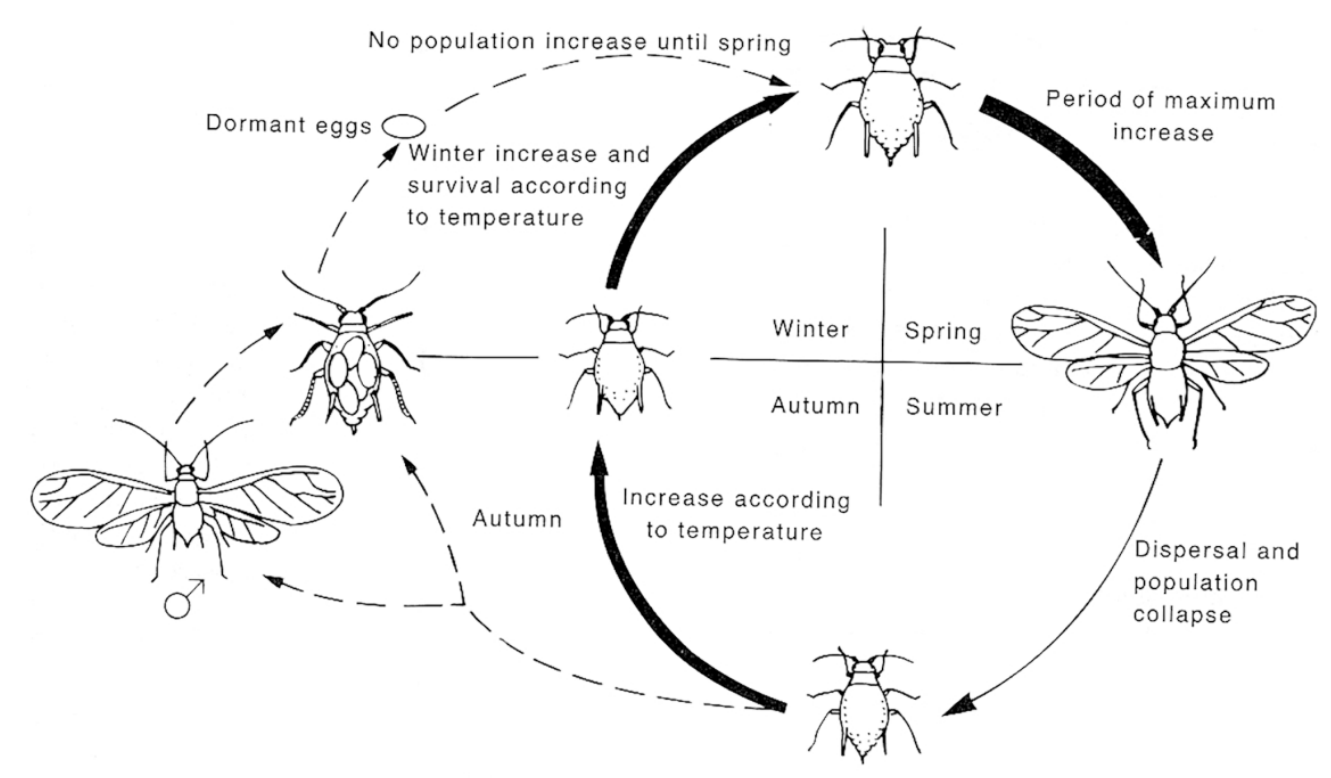

Life cycles of Elatobium abietinum

Life cycles of Elatobium abietinum after Carter \& Halldorsson (1998). 


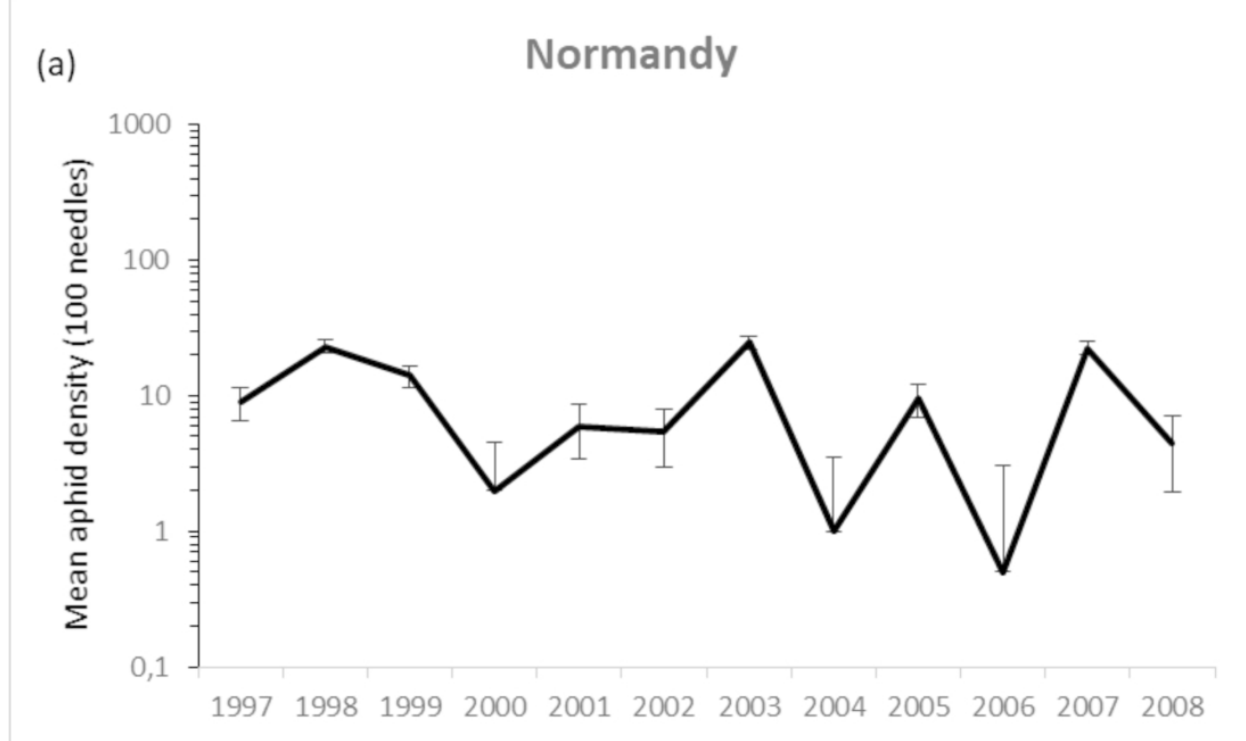

(b) Brittany

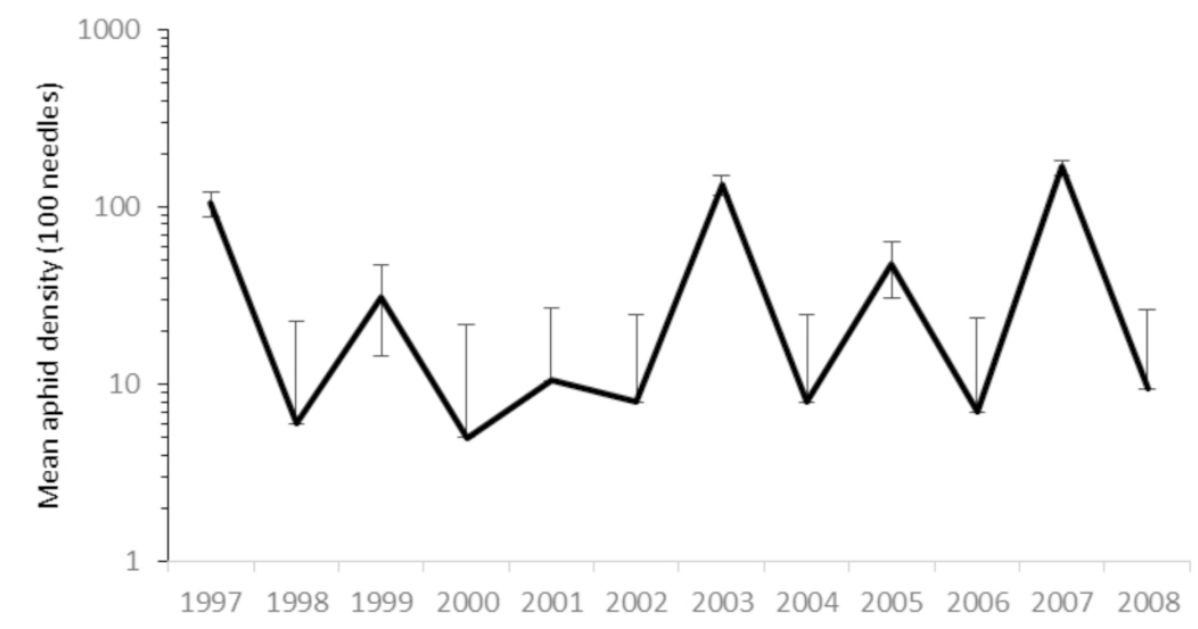

Population time series for Elato bium at Monnaye (Normandy) (a) and Malaunay (Brittany) (b), France. Mean aphid population density ( $n=400$ samples) at annual peak population (April/June) each year. 

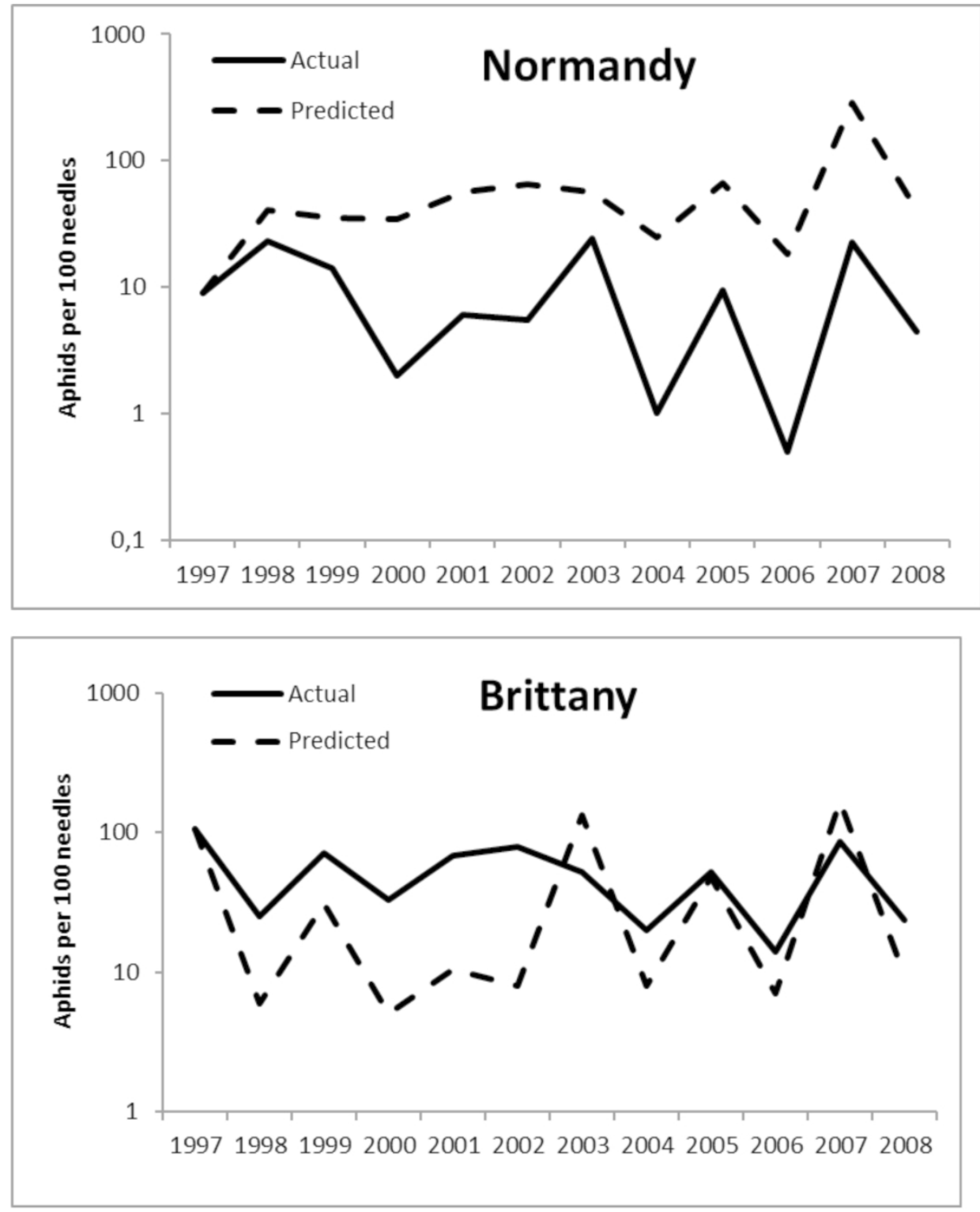

Observed (solid) and predicted (open) annual maximum population densities of the green spruce aphid in two forests, a) Monnaye forest (Normandy) and b) Malaunay forest (Brittany). Population estimates were derived from spruce needle samples. The predictions were based on the preferred model (equation 1) in Day et al. (2009), developed for northerly UK aphid populations. 


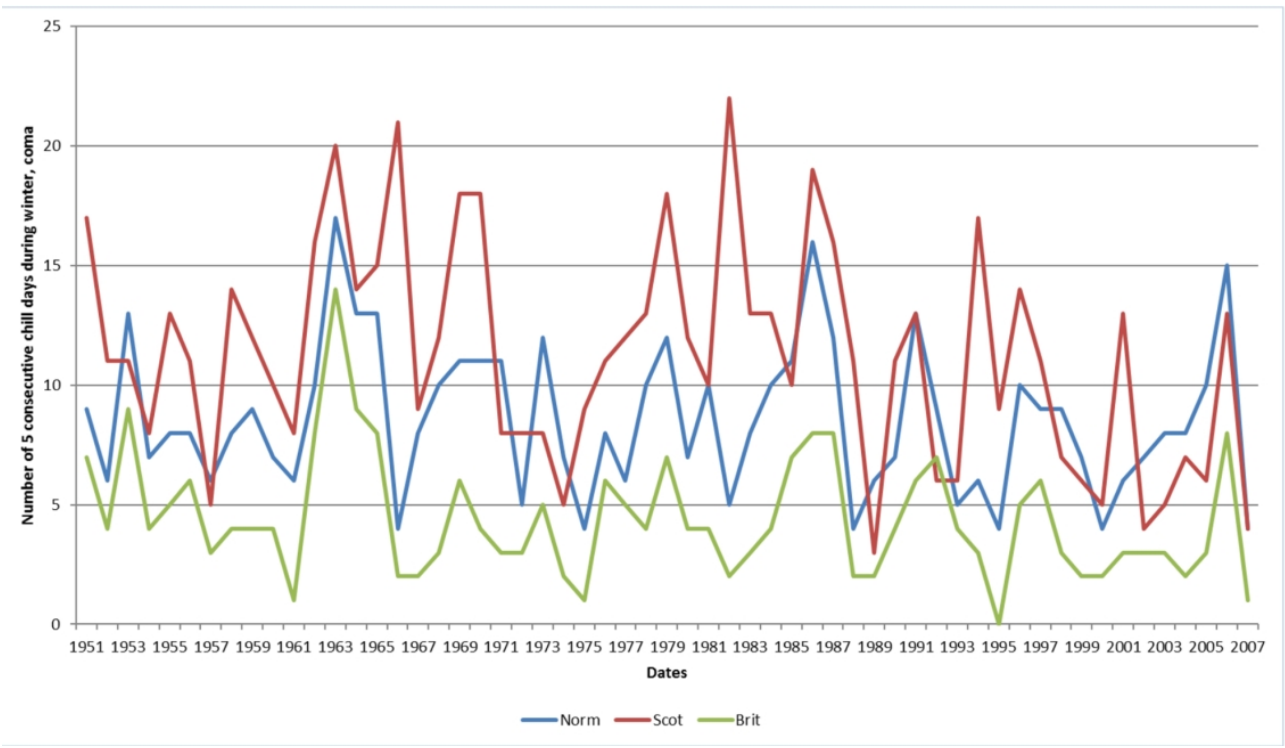

1
2
3
4
5
6
7
8
9
10
11
12
13
14
15
16
17
18
19
20
21
22
23
24
25
26
27
28
29
30
31
32
33
34
35
36
37
38
39
40
41
42
43
44
45
46
47
48
49
50
51
52
53
54
55
56
50
50




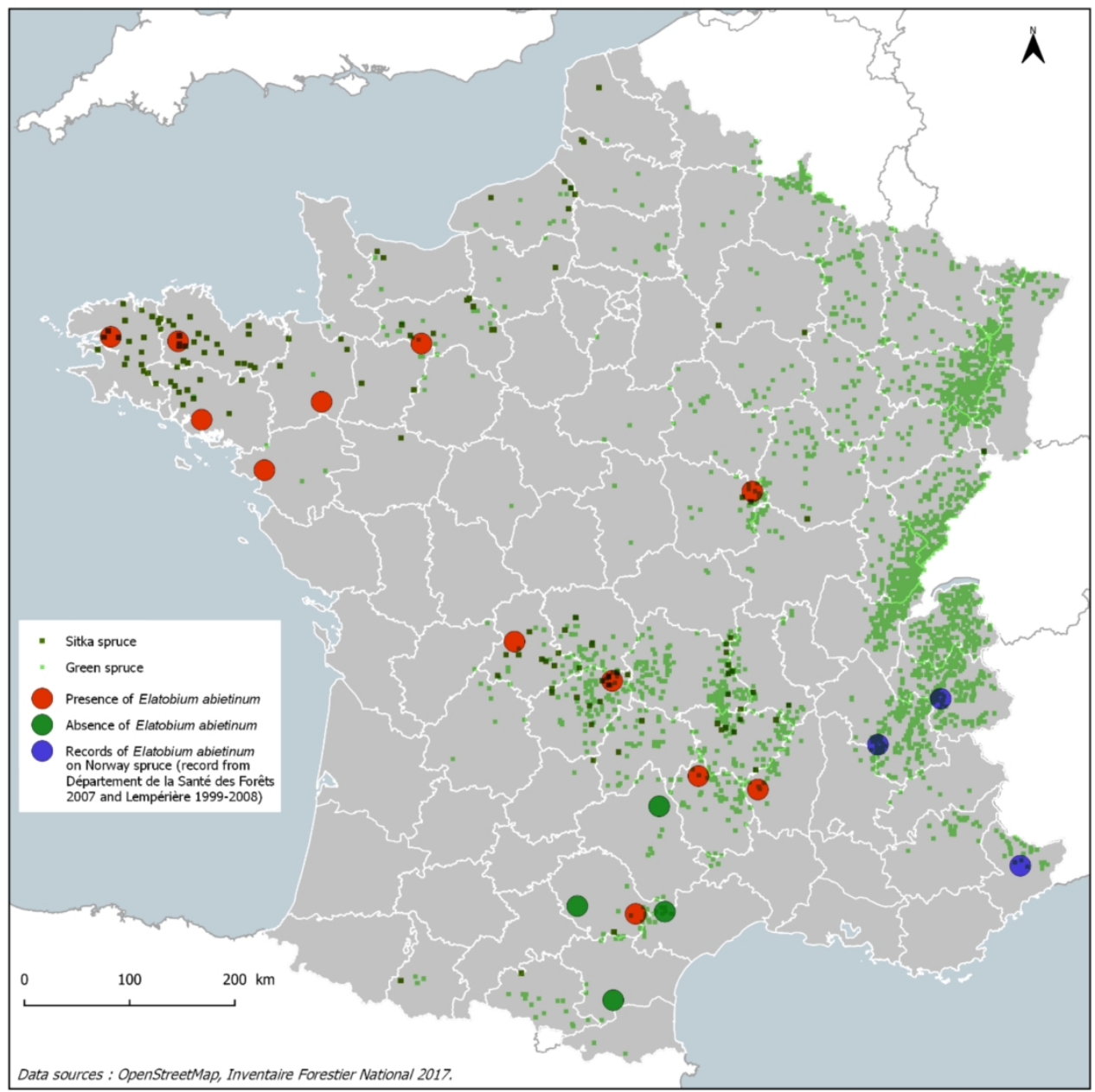

Distribution of Sitka spruce in France and location of study sites with presence and absence of Elatobium abietinum (1997-2008). 